tions a waste of time and effort. Examination of the blood is, perhaps, a wise precaution; but serological tests and E.S.R. estimations are very rarely helpful. In my patients radiography of the chest and tuberculin tests contributed nothing towards the elucidation of the problem, though the case is arguable for carrying them out on all children suffering from any symptoms whatsoever. Such procedures as blood-sugar estimations, sigmoidoscopy, and intravenous pyelography (which were carried out in a few cases) have proved unjustifiable in the absence of positive indications.

It will be seen from the above discussion that in the vast majority of cases simple investigations, which are readily carried out in one interview, alone prove necessary.

\section{Conclusions}

' Umbilical colic,' the recurrent peri-umbilical pain of childhood is, in the large majority of cases, due to non-specific mesenteric lymphadenitis. Nevertheless, umbilical colic may be the expression of other, and more serious lesions, and these should be excluded. The process of elimination can almost always be completed during the course of one clinical examination together with an accurate history, and aided by a few simple ancillary investigations.

\section{BIBLIOGRAPHY}

CAMERON, H. C. (1946), 'The Nervous Child.' London. FITZSIMONS, J. (1946), N.Z. Med. fourn., 45, 248. KINSELLA, V. J. (1940), Brit. Fourn. Surg., $27,449$.

MAITLAND-JONES, A. G. (1947), ' Diseases of Children.' (Garrod Batten and Thursfield), Vol. I, London.

MALLOY, H. R. et al. (1945), Amer. Fourn. Surg., 67, 8r. MORLEY, J. (193I), ' Abdominal Pain,' Edinburgh. POSTLEWAIT, R. W. et al. (1942), Amer. fourn. Surg., 57, 304. RAY, B. S. and NEILL, C. L. (1947), Ann. Surg., 126, 709.

ROSENBURG, S. (1937), Arch. Surg., 36, 28.

SHORT, A. R. (1928), Lancet, 2, 909.

TALBOT and BROWN (1920), Amer. Fourn. Dis. Child., $20,168$. TOVERUD, K. U. (1925), Brit. fourn. Child. Dis., 23, 22.

\title{
THE CHANGING NATURE OF GASTRIC AND DUODENAL ULCERATION
}

\author{
By J. Donaldson Craig, M.D., M.R.C.P. \\ Research Fellow in Medicine, St. Mary's Hospital, Medical School
}

\begin{abstract}
' There are gastric ulcers and there are duodenal ulcers. The differences between them are not merely geographical. In my opinion no real advance in our knowledge of the aetiology, clinical manifestations or treatment of these two diseases, gastric ulcer and duodenal ulcer, will be made if we speak of them as one.'
\end{abstract}

\section{Moynihan. (I 928).}

\section{Introduction}

Acquired disease is the product of disharmony between constitutional and environmental factors. It is therefore to be expected that in the course of the years there should be considerable change in the nature, prevalence and distribution of many diseases. In the present survey, an attempt has been made to trace the evolution of gastric and duodenal ulceration from earliest times to the present day.

From this review, it emerges that not only have the total incidence, the age and sex distribution and the clinical picture of peptic ulceration changed very considerably, but that the evolution of gastric and of duodenal ulcer have been along very different lines. It is therefore suggested that although, as postulated by Hurst, individual constitutional variations may play a large part in the genesis of peptic ulcer, environmental factors are of even greater importance, and it is to such factors that attention should be directed in an attempt to control these diseases. Further, the history of the development of gastric and duodenal ulceration through the ages being so distinct, one is inclined to suspect that the differences between the two principal types of ulcer are more than geographical. It should not therefore be too readily assumed that gastric and duodenal ulceration are of entirely similar pathogenesis.

\section{The Classical Period and Middle Ages}

The earliest reference to gastric disease is found in the Ebers Papyrus (circa I500 B.C.) in which cancer of the stomach is mentioned. Hippocrates was familiar with haematemesis and melaena, both of which he regarded as of serious import, particularly if associated with fever, but there is nothing in his writings to suggest that he recognized the ulcer syndrome. Gastric ulceration as such is first 
mentioned by Celsus, in his 'de Medecina' (A.D. 30). Dealing with the rules governing diet for the preservation of health, he wrote, 'but if ulceration attack the stomach . . . milk and glutinous food are given, but not to satiety ; all acrid and acid things are withheld.' It is tempting to believe that this fundamentally sound counsel was based upon actual observation of cases of gastric ulcer occurring in the upper strata of Roman society in which he practised, but this is the sole reference which can be found. Careful search has failed to discover either clinical or pathological description of the condition and his advice would be equally valid for the dyspepsia, which, it may legitimately be inferred, was liable to follow over-indulgences in food and drink. Galen (A.D. I31-200), referring to the prevalence of dyspepsia, mentioned haematemesis, and gave recognizable descriptions of both dysenteric intestinal ulceration and hepatic cirrhosis, but he did not mention gastric ulceration. By this time dissection of the human body had been declared illegal, a disadvantage which would effectively prevent the recognition of gastric ulcer. It was not until the fifteenth century, in Italy, that human dissection appears to have become at all a common practice again, and it is therefore not surprising that all consulted writings of the middle ages are devoid of references to the study of gastric pathology, a subject which does not reappear in the literature until the end of the sixteenth century.

\section{The Sixteenth to Eighteenth Genturies}

The writings of many morbid anatomists during this period are open to the suspicion that they were based more upon imagination than actual observation. Such was the delay in carrying out postmortem examination, in many instances, that even John Hunter regarded as normal the finding of gastric contents in the peritoneal cavity, the stomach having undergone self-digestion after dissolution of ' the vital principle' which normally protected it from this fate. Clearly then, no significance can be attached to absence of accounts of peptic ulceration from the works of many of the writers of this period. These shortcomings were however, by no means universal, and by the end of the r8th century the literature contained several carefully documented case histories of fatal peptic ulcer, writings which have the ring of truth about them and present every evidence of having been compiled by reliable witnesses. The earliest case history of this period is that recorded by Marcellus Donatus of Mantua in 1586 . Describing his postmortem examination of a fatal case of pyloric stenosis he wrote, ' at the pylorus or lower orifice we found that the inner coating was ulcerated, and we had no doubt that this had been the cause of the malady.' The antecedent history briefly outlined is suggestive of a diagnosis of gastric carcinoma rather than of simple ulceration. The significant point is that this is not only the earliest record of a case of pyloric stenosis but the only example which has come to light in a thorough search of the literature over many years of this period.

One other case history is perhaps worth recounting in some detail, for its historical as well as its medical interest. Ironically, this, the first description of the clinical features of perforation comes, not from the profession but from a laywoman, Madame de la Fayette, lady-in-waiting to Princess Henrietta Maria, daughter of Charles I of England and wife of Philip, Duke of Orleans. The Princess, 26 years of age, had always been of frail constitution, subject to recurrent attacks of $\triangle$ right-sided pain. While staying at the Court of iv Versailles, she ate a large midday meal and, as was her wont, retired to her couch for the afternoon. On awaking she complained of a return of her abdominal pain and was given a cup of chicory water to produce relief. Immediately after drinking it she collapsed, crying out in pain, and ' turned pale with a wan lividity which astonished us.' The royal physician, on being called, tactfulle diagnosed the illness as an attack of colic, and them apparently proceeded to treat her as a case of $\overrightarrow{0}$ poisoning. His insight into the ways of his roya betters, however, was, this once, unrewarded, foD the carminative and purgative oils which he prescribed merely increased the poor lady's pain, and she died after drinking a bowl of soup, just nine hours from the onset of her collapse. It appears that attendance at post-mortem examination at that time was one of the duties or privileges of the spiritual adviser of the deceased, for we have an account of the autopsy from Bossuet, who surpassed even his normal flight of eloquence in making the funeral oration, in which he gave dark hints of his belief that death had come from poisoning. A fairly full account of the necropsy findings is contained in the "Memoirs of a Surgeon to the King of England, who was present at the Opening of the Body of Madame.' Foetid gas escaped when the abdomen was opened; the omentum was gangrenous, the intestines discoloured; the peritoneal cavity contained a large quantity of oily fluid but, in contrast with the intestines, the stomach was normal save for a small hole anteriorly near the lesser curvature ' due to the inadvertence of the surgeon who cut it.' Our informant remarks, with evident self-satisfaction, that this alleged breach of technique was overlooked by all others present. Like Bossuet, the court physicians quietly assumed that death had resulted from administration of poison smuggled from Rome by the Chevalier de Lorraine, one of Philip's inti- 
mates, but, with greater prudence, the cause of death was officially stated to be 'une trop grande effusion de bile.' 'There the matter rested till 1872 when Littre, familiar with the clinical picture of perforation from the teachings of Cruveilhier and Ludwig Mueller, reopened the discussion. $\mathrm{He}$ pointed out the true nature of the seizure, remarking that the oil found in the peritoneal cavity was that which had previously been given medicinally, the hole in the stomach being of course the perforated ulcer.

Although the true causation of this particular seizure was overlooked at the time, during the eighteenth century several writers described cases of fatal gastric perforation or haemorrhage. Bonetus of Geneva in 1700 wrote of a girl of 18 who died of peritonitis four days after melaena, autopsy showing the presence of a perforated gastric ulcer. Four years later, M.P.E. Littre found a prepyloric ulcer in a man who had died of haematemesis and melaena, and in 1729 Christopher Rawlinson described a case of pyloric stenosis of four years standing, terminating in gastric perforation.

The earliest recorded instance of duodenal perforation is that described in 1746 by George Hamberger of Jena, a fatal seizure in an apparently healthy young woman, necropsy showing the presence of what appears to have been a chronic ulcer of duodenum. In a footnote to his paper on lead colic, Sir George Baker described in 1772 a fatal case of haematemesis and melaena from duodenal ulceration.

All these however were merely isolated instances. None of the writers appears to have had experience of more than one case nor had any of them recognized the disease in the living subject. Morgagni, whose knowledge was derived not only from clinical studies but from careful post-mortem examinations, carried out in nearly every instance before rigor mortis had set in, obviously regarded peptic ulceration as a rarity. He quoted several examples from contemporary physicians and described a few cases of his own, but even of this very small series at least two are almost certainly instances of carcinoma. Only once does he refer to the finding of an abnormal condition of the duodenum, and that is in the case of a woman who, having long suffered from hypertensive heart failure, collapsed and died suddenly, autopsy showing the presence of multiple erosions of the stomach and duodenum.

All these are instances where the nature of the disease was recognized only at post-mortem examination, and there is little detail of antecedent symptoms. The earliest well documented case history recording such symptoms is that written by Jacobo Penada of Padua, in 1793. Dominico
Miazzo, a butcher of that city, a man of immense physical strength and grossly intemperate habits, was in the habit of eating but little, i.e. little as judged by the prevailing standards of the time. Despite these regrettable deviations from the current mode of behaviour, he remained in excellent health and worked hard at his trade until May 25th, I79I, when he began to suffer from para-umbilical pain of great severity, occurring immediately after meals but unaccompanied by any desire to vomit. After an hour or so the pain generally abated sufficiently to allow him to continue with his work. Having apparently but little faith in the ministrations of his physician, and lacking the benefit of education in such matters as is now provided by advertisements in the lay press, Dominico concluded that his pain resulted from ' the flatulence in the intestinal tubes.' Determined to evict this unwanted flatus, he embarked on an enthusiastic course of self medication, taking large amounts of 'spirits of wine and other spirituous liquors.' Little is recorded of his response to this heroic form of treatment save that his pains continued and became more severe, until the 20 th of June, I79I, when he developed 'suppression of the urine and faeces.' Fortified, no doubt by his medicaments, he ignored these distresses and continued at work until the early morning of the 23 rd when he collapsed with an extremely severe attack of abdominal pain. Penada's description of the subsequent course of events is brief and masterly. ' His pulse was feeble but irregular, but there was no trace of fever. His face was pale and pinched. The eyes were sunken in and the extremities cold to the touch. The muscles of the abdomen were tense, and he was doubled up. From hour to hour our patient grew worse . . . and at sunset he died.'

Although Padua at that time was a flourishing medical centre, it is clear from this account that the case was regarded as unique. Great interest was aroused among all the physicians of the city, most of whom attended the post-mortem examination on the following day. It was then found that the peritoneal cavity was full of fluid : the stomach appeared normal, but " that which formed the special interest of the present case and the subject of our discourse was in the duodenum.' A beautiful line engraving accompanying the publication tallied closely with Penada's description of an oblong hole in the first part of the duodenum lying in the midst of ' a peculiar morbid ulcer which was of considerable thickness' hard, indurated, and surrounded by multiple small ulcers extending onto the posterior duodenal wall.

Reading such case histories as this, obviously the work of skilled and diligent inquirers, one cannot help feeling that such illnesses must have been of relatively rare occurrence in their practice. 
The writings of such morbid anatomists as Morgagni are obviously the work of masters who were aware of the occurence of peptic ulcer and displayed a keen interest in the disease. One is therefore left with the impression that, had peptic ulceration been as prevalent then as it is today, it would have been discovered and reported much more often.

This belief in the uncommonness of peptic ulcer is borne out by reference to contemporary works on military medicine. In his work Diseases of the Army, published in 1753, John Pringle gave the first written account of those maladies to which armies in the field are peculiarly subject, devoting chapters to dysentery, fevers, pneumonia, phthisis, jaundice, ophthalmia, quinsy, and ' the itch' problems still important in military medicine, but the heading 'Inflammation of the Stomach and Intestines' is followed by only a few lines. On the subject of the effect of army diet, a factor which he regarded as of little import, he remarked ' a soldier in time of war is by the smallness of his pay, secured against excess of eating, the commonest error in diet.' Macgregor, in another excellent work 50 years later dealt with the same type of subject matter, but apart from discussing dysentery, he made no reference to digestive diseases.

It is to be remembered that, at this time, men passed into the army without preliminary medical selection and thereafter lived under most arduous conditions. When one remembers the rapidity with which previous sufferers from peptic ulceration broke down, many of them seriously, under the incomparably better conditions prevailing in the armed forces during the late war, then it becomes apparent that in this particular age and sex group, peptic ulcer must have been exceedingly uncommon. So, making every allowance for the difficulties of diagnosis and the limited nature of pathological investigation, one is forced to the conclusion that, till the end of the eighteenth century, in Europe peptic ulcer was a rare condition. From almost every important medical centre isolated cases had been reported, and the majority of 'them appear to have aroused considerable interest, yet, with the exception of Morgagni,ewhose experience was extremely extensive, no one had reported a series, nor, since the time of Celsus had any suggestions been made regarding treatment.

\section{The Late Eighteenth and Nineteenth Centuries}

To Matthew Baillie, nephew of John Hunter, must be accorded credit for the first successful attempt to recognize the symptoms of gastric ulcer. In 1793 he outlined the protracted course of the disease, attended by abdominal pain and vomiting. Clearly distinguishing the condition from carcinoma, he described the round, punchedout appearance of the ulcer with little surrounding inflammation, 'sometimes destroying a portion of all the coats, forming a hole in the stomach.' Six years later he published drawings of two specimens, the one showing four ulcers in the stomach and one in the duodenum, the second, 'from $\mathrm{Mr}$. Hunter's museum ' being an example of perforated gastric ulcer.

In 1817 , Benjamin Travers and John Crampton, quoting from Morgagni, described from their joint experience, three instances of perforated gastric ulcer ' which, although not of frequent occurrence has been described by several anatomists.' The description of the clinical sequence is so complete and so concise that one is justified in believing that the authors would not overlook the true nature of cases of perforation coming within their practice, yet their total experience comprised only three cases. Abercrombie of Edinburgh (1828) described instances of fatal perforation, haemorrhage, and gastro-colic fistula, but he failed to draw a clear distinction between simple ulceration and gastric carcinoma, at least one of his cases being an example of the latter. Stressing the difficulties encountered in diagnosis of digestive disorders he noted that in the great majority of hi̊ิ cases coming to post-mortem, he was unable to find any lesion to account for the symptoms occuro ring during life. He gave advice on recognition of duodenal disease in life, writing "The leading peculiarity of disease of the duodenum so far as we are at present acquainted with it, appears to be that food is taken with relish and the first stage of digestion is not impeded, but the pain begins about the time the food is passing out of the stomach or about two to four hours after a meal.' He quoted several fatal cases of perforation or haemorrhage, the diagnosis being confirmed at post-mortem examination.

Meanwhile, French physicians were keenly studying gastric ulcer, most of their findings being published in thesis form. Their work was largely embodied in Cruveilhier's masterly description (1835) accompanied by beautifully clear illustrations. Distinguishing carcinoma from simple ulcer and defining the latter as 'une perte de substance spontanée,' he noted the prevalent occurrence on the lesser curvature, posterior surface and in the pyloric region. He accurately described the symptoms, chief of which was "tristesse insurmontable,' noted the common complications, and outlined the methods of treatment he had successfully, employed, these being based on rest and dietary control.

This work of Cruveilhier, which achieved widespread recognition, was carried out largely on 
hospital in-patients, a highly selected group and did not, therefore, give a representative picture of the disease as it affected the population at large. The studies of William Brinton, (1857) did not suffer from this disadvantage. Reviewing a collected series of post-mortem cases, he concluded that gastric ulcer was twice as common in women as in men, that about five per cent of the population developed gastric ulcer at some time or other in their lives, and that, in about half of those affected, spontaneous healing occurred. He also believed that the liability to ulceration increased with age, but since the series on which this argument was based included not only active ulcers but scars of indeterminate age, this conclusion cannot be accepted. His views on the clinical features of gastric ulcer were based on a study of hospital out-patients, of whom he saw no less than 4,000 new cases every year. Of these, some 40 patients, i.e. about one per cent, he diagnosed as suffering from gastric ulcer and, although the difficulties inherent in out-patient practice prevented his confirming the diagnosis in every case, yet he was able to follow a sufficient proportion of these patients to the post-mortem room to convince himself of the substantial accuracy of his conclusions. The description of the clinical features of gastric ulcer was extremely full and accurate. Perforation, he believed, occurred in not more than one case in eight, while haemorrhage, by many previously regarded as a cardinal symptom, affected not more than one sufferer in ten or twenty. It has already been noted that both clinically and pathologically the diagnosis was made twice as commonly in women as in men. It was therefore remarkable that haemorrhage occurred twice as often in men as in women, in both sexes being most prevalent in the fifth decade and uncommon in young women. Of 199 cases of perforation, 139 occurred in women, chiefly in the age group 14-30, whereas in men perforation was most common in the fifth and sixth decades. This age and sex distribution is very different from that obtaining today, and the discrepancy is to be explained, partly, by the former relative commonness of acute perforating ulcer in young women, many of whom had some degree of anaemia.

The association of the chlorotic state and gastric disturbances is an interesting one. Latour, in 1828 , writing on gastric ulceration and haemetemesis, noted that in several cases in his experience postmortem examination had failed to reveal any lesion of the alimentary tract to account for the haemorrhage. Ashwell of Guy's Hospital, in 1836, in an excellent account of the severe anaemia in young women suffering from amenorrhoea, wrote of " a vicarious discharge of blood from the stomach by vomiting' which might produce considerable debility and he stressed that even in milder cases there was 'some impairment of digestion.' In Brinton's series, normal menstruation was the rule in sufferers from chronic ulceration, except in the small proportion who had had severe haemorrhage. The majority of cases of perforation in young women however, he regarded as being in a class apart. In these there was but a brief antecedent history of dyspepsia, and at post-mortem examination the ulcer, clear-cut and devoid of surrounding fibrosis or other evidence of attempted healing, was clearly different from the scarred ulcers occurring in older people. While recognizing the anaemia of these patients, Brinton did not accept them as typical examples of chlorosis, contrasting their pallor with the typical greenish hue of the latter, but one wonders if the difference which he stressed was more one of degree than fundamental nature. He was however quite emphatic that vicarious menstruation was an entirely mythical concept.

He believed gastric ulcer to be most common in the hospital class of patient-' those who suffer from the ills implied by penury in this metropolis, excessive toil, insufficient and unwholesome food, foul air, mental anxiety and those habits of intemperance which are the effects as well as the cause of such misery,' and these remarks represent the earliest attempt to elucidate the pathogenesis of ulceration.

Neither Cruveilhier nor Brinton mentioned morbid conditions of the duodenum. Cooper (i839) described two fatal cases of duodenal ulcer following burns, and three years later, Curling, to whom the credit for recognizing this syndrome is generally accorded, published a small series, including the two cases already reported by Cooper. Hodgkin, lecturing in 1840 , stated that he had rarely encountered duodenal ulcer, and that in the cases where it had been present it was sometimes the result of tubercle or breakdown of adjacent neoplastic masses. Trier, of Copenhagen (1863), was able to collect only 54 recorded cases of duodenal ulcer, including 26 of his own, gathered over a period of twenty years. From his extensive investigations he concluded that ulceration was ten times more common in the stomach than in the duodenum, men being the principal sufferers from the latter condition. He divided his cases into two groups, viz. those who presented after perforation having previously enjoyed good health, and a second class who had had previous symptoms indistinguishable from those of gastric ulcer.

Bucquoy (1887), stressed the importance of duodenal ulceration, primarily a disease of males, as a condition to be distinguished from gastric ulcer. He instanced five cases, all of whom had bled, and noted the absence of vomiting and the 
maintenance of appetite, particularly after haemorrhage. Perhaps his most interesting patient was a young commandant of artillery, who suffered severe abdominal pains three hours after meals until one of his travelling companions on a transAtlantic ship advised the taking of sodium bicarbonate, which produced rapid relief. It almost appears that the laity had anticipated Sippy by some half century in the recognition of this sovereign palliative.

Brinton's views on the incidence of gastric ulcer and its complications were confirmed by other writers, including Samuel Fenwick, who in 1868 again stressed the clinical and morbid anatomical differentiation between chronic and acute perforating ulcer. He noted that the latter might give rise to haemorrhage rather than perforation in young women, but agreed with Brinton that on the whole, haemorrhage was more common in men. In the years up to the turn of the century, haemetemesis from acute ulceration appears to have become progressively more common in women. Osler, in his first text book, noted the frequent association of chlorosis and gastric ulcer in young women, but at this time he had seen only nine cases of duodenal ulcer, seven of them in men. Perry and Shaw, in 1893 , reviewed the reports of the $17,65^{2}$ necropsies which had been performed at Guy's Hospital during the years 1826-92, beginning with 'Dr. Hodgkin's green inspection books,' and concluded that duodenal ulcer had been found in only 0.4 per cent of cases, in about half of which it had been associated with burns, Bright's disease, or general septic conditions.

\section{The Twentieth Century}

During this period of history considerably more data became available which permit of fairly definite conclusions on the changing nature and incidence of peptic ulceration in Great Britain. Advances in surgical technique had made abdominal operation relatively safe, thus permitting the confirmation of diagnosis. Hurst and Stewart, studying a very large post-mortem series, conducted with especial regard to the incidence of the various forms of peptic ulcer, had shown beyond doubt the magnitude of the problem. Diagnostic radiology of the alimentary tract became a reliable routine investigation. As from 1901, gastric ulcer was shown under a separate heading in the Registrar General's returns, and duodenal ulceration was separately listed as from I9II : the figures, so provided, furnish a wealth of information. Finally, the two major wars necessitated for the first time a comprehensive health survey of a large proportion of the population.

At the turn of the century gastric ulcer still predominantly affected women. An increasing pro- portion of cases of haemetemesis, formerly confined to males and older women, now began to occur in younger females. It was observed that, although the diagnosis of gastric ulcer was made in women more often than in men, women were less likely to die from the disease. The Fenwicks' analysis of a. post-mortem series of cases of gastric ulcer is shown in Table I.

\section{Males Females per cent. per cent.}

Acute gastric ulcer $\quad 3 \quad 30$

Chronic gastric ulcer $\quad 48 \quad 19$

It will be noted that the deaths in males and females are approximately equal, whereas in Brinton's series females predominated by two to one.

This apparently low mortality in females was commented upon by Hale White in 1906 . He pointed out the commonness of the syndrome of chronic dyspepsia, chlorosis, amenorrhoea, and recurrent haemetemesis in women between the ages of 20 and 40, rarely fatal and seldom complicated by perforation or by pyloric stenosis, which in a series published by Somerville Hastings a year later was twice as common in men as in women. In the few instances in which operations had been undertaken to control haemorrhage no macroscopic lesion had been discovered. Accordingly, conservative treatment was advised for these cases for which Hale White coined the term ' gastrostaxis,' and which are now recognized as examples of acute superficial ulceration. That the majority of cases of haemetemesis at this time were due to this condition is suggested by the low mortality-four per cent.-in Conybeare's series of 600 cases treated between I9II and I920, a figure which has not been equalled in any recent series in this country despite advances in treatment, in particular the introduction of drip transfusion and Meulengracht's practice of early feeding. In Brinton's experience such cases were infrequent. The condition appears to have been one of increasingly common occurrence during the last quarter of the nineteenth century, and, like the associated disease, chlorosis, it virtually disappeared at about the time when the first world war brought about the emancipation of women.

In the early years of the century nearly all authorities still regarded duodenal ulcer as a rare disease. In 1900 the Fenwicks were able to quote over 200 references in the bibliography on duodenal ulcer, yet, for all their extensive experience and keen interest they were able to gather only 68 cases, 25 of them acute ulcers resulting from burns, acute infections and pyaemic states. The work done was out of all proportion to the number of cases discovered. It has generally been advanced that this apparent rarity of duodenal ulcer was the 
result of failure to recognize the condition, and undoubtedly many cases were missed. None the less, when one views the situation against the broad background of earlier writings, it is difficult to escape the conclusion that this improvement in diagnosis occurred at the same time as an increase in the relative and absolute frequency of duodenal ulceration. Review of more recent years provides strong evidence of still greater prevalence and this probability becomes a virtual certainty.

In Moynihan's first published series of 162 cases of relatively unselected examples of chronic ulcer dyspepsia, the lesion was found in the duodenum $5 \mathrm{I}$ times, a ratio of duodenal ulcer : gastric ulcer of approximately $1: 2$. By 1926 , in his complete series of 798 cases, he had found a duodenal ulcer in 7I per cent. of cases, and both duodenal and gastric ulcer in a further four per cent., this latter experience tallying with Wilkie's finding that duodenal ulceration was six times more common than gastric ulceration. That the absolute as well as the relative incidence of duodenal ulcer has increased is borne out by almost every review published. For example, in 1906, 26 cases of duodenal ulcer were admitted to the Edinburgh Royal infirmary, 22 of them for perforation, whereas in 1926 there were 236 admissions of which 102 were for perforation.

The high incidence of peptic ulceration was brought out by the publication of the investigation of 4,000 consecutive post-mortem examination; in Leeds by Hurst and Stewart, who found active gastric ulcer in 2.23 per cent. and active duodenal ulcer in 3.83 per cent., healed scars bringing the total incidence to approximately ro per cent. of all cases. Duodenal ulcer was more common in male than in female in the ratio of $7: 2$, but females were more more frequent sufferers from gastric ulcer in the ratio $10: 8$. These findings however cannot be held to give an accurate idea of the incidence of peptic ulceration in the community today. The investigation was based on a selected section of the populace, viz. those who for one reason or another were admitted to hospital and, having been admitted, died. Secondly, there is every reason to believe that the incidence of the various forms of peptic ulceration has undergone further change since this series was investigated. The statistics of the Registrar General have been analysed over the past forty years (Tidy 1944, Craig 1948) and these provide striking evidence of the increase in peptic ulceration. Only about one in twenty of peptic ulcer sufferers dies as the direct result of this condition, so these figures do not give an entirely representative picture as they affect the populace at large, but certain trends are apparent.

The mortality from gastric ulcer in women has greatly decreased, particularly in the younger age groups, largely as the result of the virtual disappearance of acute ulceration. In all other groups mortality has either remained steady despite therapeutic advance, or has actually increased. This increase is most marked in men over 45 , and the change is only partially due to the general ageing of the population. Although it is agreed that duodenal ulcer is now much more common than gastric ulcer yet gastric ulcer is responsible for about two out of every three peptic ulcer deaths. It might be argued that this is an artefact due to faulty certification, but of peptic ulcer deaths in the Services during the war about 60 per cent. were due to gastric ulcer. It is in accord with experience to assume that in some 90 per cent. of instances the diagnosis was confirmed by autopsy, so that the figures quoted probably give a fairly representative indication of the relative mortality of the two diseases.

Dyspepsia presented no great problem to earlier military surgeons and in the first world war digestive diseases ranked low in the list of disabilities. During the late war, duodenal ulceration was second in importance only to neurosis as'a medical cause of invalidism, and one is therefore forced to the conclusion that in the period between the two wars there had been a very great increase in the number of young men affected with this disease. In fact gastric and duodenal ulceration as we know them today are disfases of the twentieth century.

\section{Conclusions}

It would therefore appear that gastric ulceration approached its present prevalence sometime in the first half of the nineteenth century, since when its distribution and clinical pattern have changed considerably. Duodenal ulcer seems now to present the same clinical picture as formerly, but it has become very much more common during the past fifty years, and now represents a most important source of chronic ill-health in young men. These changes are, presumably, the result of the operation of changing environmental factors, and so the view that the increasing prevalence of these diseases is a concomitant of life under modern conditions, is, to a large extent, substantiated. In all probability, the nature of these diseases will continue to change. They may even disappear almost entirely as has the acute gastric ulceration of young women, either as the result of therapeutic advance or from the elimination of those environmental factors which favour their development. In the meantime, the great body of sufferers may derive a little consolation from Voltaire's remark that 'it is a pleasant fact that thought entirely depends upon the stomach and that, in spite of that, the best stomachs are not the best thinkers.' 


\section{Summary}

I. The history of gastric and duodenal ulceration is surveyed.

2. From this review it appears that gastric ulcer was uncommon till the middle of the nineteenth century, and duodenal ulcer was rare till the beginning of the present century.

3. Gastric ulcer has become a comparatively rare disease in females and, in particular, the acute type of ulcer frequently associated with chlorosis is no longer encountered.

4. Duodenal ulcer in males became very much more common in the period between the two major wars.

5. The increased mortality from peptic ulcer is largely accounted for by the greater number of deaths of men over 45 from duodenal ulcer.

6. Although duodenal ulcer has increased in frequency, there is no evidence of change in its clinical pattern, but gastric ulcer has clearly changed greatly.

7. The causes of these changes and consequently of the disease themselves are to be sought in environmental changes rather than constitutional factors.

8. There is historical support for the suggestion that these diseases are yet another penalty of the present day mode of life.

9. It is to be expected that the nature and incidence of these diseases will continue to change.

\section{BIBLIOGRAPHY}

ABERCROMBIE, J. (1828), ' Diseases of the Stomach.' Edinburgh. ASHWELL (1836), 'Chlorosis and its Complications.' Guy's Hospital Reports, i, 529.

BAILLIE, M. (I793), 'Morbid Anatomy of Some of the Most Important Parts of the Human Body.' London.

BAKER, Sir G. (1772), Med. Trans. Coll. Phys., i, 175.

BONETUS, T. (1700), ' Sepulchretum sive Anatomia Pratica.' Lib. iii, Sect. XXI, Observatio XXV.
BRINTON, W. (1857), ' Ulcer of the Stomach.' London.

BUCQUOY, S. (1887), Arch. Gen. de Med., 398, 526, 69 r.

CLARK, A. (1867), Brit. Med. f., i, 661, 731.

CONYBEARE, J. J. (1935), Lancet, ii, ro1 7 (and quoted by Hurst). COOPER, S. (1830), Lond. Med. Gaz., $23,837$.

CRAIG, J. D. (1948), B.M.Y., (in Press).

CRUVEIL HIER, J. (1835), ' Anatomie Pathologique,' i, X, I. Paris. CURLING, T. B. (1842), Med. Chir. Trans., 25, 260.

DONATUS, M. (1586), De Medica Historia Mirabili, Lib. IV, Cap. iii, 196.

FENWICK, S. (1868), 'The Morbid States of the Stomach and Duodenum.' London.

FENWICK, S. and FENWICK, W. S. (I900), "Ulcer of the Stomach and Duodenum.' London.

HÁMBERGER, G. (1746), ‘de Ruptura Intestini Duodeni.’ Jena. HASTINGS, S. (1907), Med. Chir. Trans., XIX, 335.

HAWKINS, H. P. and NITCH, C. A. R. (1907), ibid, XIX, 339. HODGKIN, T. (1840), 'Lectures on the Morbid Anatomy of the Serous and Mucous Membranes,' Vol. ii, 368.

HUNTER, J. (1786), ' Observations on Digestion.' London.

HURST, A. F. and STEWART, M. J. (1929), 'Gastric and Duodenal Ulcer.' Oxford.

LATOUR (1828), ' Histoire Philosophique et Médical des Haemorrhages.' Paris.

LITTRE (1872), ' Médecine et Médecins.' Paris.

MACGREGOR, J. (1804), 'Medical Sketches of the Expedition to Egypt from India."

MORGAGNI, J. B. (1769), ' Seats and Causes of Diseases,' ii, 244 MOYNIHAN, B. G. A. (1901), Lancet, ii, 1656.

MOYNIHAN, B. G. A. (1905), Lancet, i, 340 .

MOYNIHAN, B. G. A. (1905), 'Surgical Treatment of NonMalignant Disease of the Stomach.' London.

MOYNIHAN, B. G. A. (1910), 'Duodenal Ulcer.' London.

MOYNIHAN, B. G. A. (1928), Brit. Med. F. ii, 1021.

OSLER, W. (1892), ' Principles and Practice of Medicine.' London. PERRY, E. C. and SHAW, W. E. (1893), Guy's Hospital Reports, 50, I7I.

POWER, d'A. (1925), Med. F. and Record, 122, 415.

PRINGLE, J. (r753), 'Diseases of the Army.' London.

PENADA, J. (I793), 'Saggio d'osservazioni e Memorie Sopra alcuni casa Singolari.' Padua. (Quoted by Malloch).

RAWLINSON, C. (1727), Phil. Trans. Roy. Soc., XXXV, 36r. REGISTRAR GENERAL (1905-45), Statistics.

TIDY, Sir H. (1944), Brit. Med. F., i, 677.

TRAVERS, B. (1817), Med. Chir. Trans., VIII, 232.

TRIER, F. (1863), 'Ulcus Corrosivum Duodeni.' Copenhagen.

TRIER, F. (1864), Gaz. Hebdomadaire, 2nd Series, i, 475. (Review). TRIER, F. (1864), Brit. and Foreign Med. Chir. Review, xxxiii, 157 (Review).

WHITE, W. H. (I90I), Lancet, i, 1819.

WHITE, W. H. (I906), ibid, ii, I 189 .

WILKIE, W. P. D. (1927), ibid, ii, 1228.

\section{H. K. LEWIS \& Co. Ltd.}

Medical Publishers and Booksellers

\section{GOWER STREET LONDON, W.C.1}

(Adjoining University College and Hospital)

Telephone: EUSton 4282 (5 lines)

Telegrams : Publicavit, Westcent, London

Established 1844

\section{Medical Lending Library}

ANNUAL SUBSCRIPTION from ONE GUINEA

For the CONVENIENCE Of POST-GRADUATE STUDENTS SHORT PERIOD SUBSCRIPTIONS ARE ARRANGED - for 3 or 6 months Detailed Prospectus on application

The Library Catalogue revised to December, 1943, containing classified index of authors and subjects. To subscribers, 12s. 6d. net; to non-subscribers, 25s. net, postage 9d. SUPPLEMENT, 1944, TO DECEMBER, 1946

To Subscribers, 2s. 6d. net; To Non-Subscribers, 5s. net, postage $4 d$. NEW BOOKS ADDED IMMEDIATELY UPON PUBLICATION 